\title{
Analysis of Earth Induction Effects on Ground Based Observations of ULF Pulsations near $L=4$
}

\author{
C.W. ANDERSON \\ Bell Telephone Laboratories, Whippany, New Jersey, U.S.A.
}

(Received December 23, 1974; Revised July 16, 1975)

\begin{abstract}
The use of polarization parameters and amplitudes of spectral components of ULF pulsations observed at the earth's surface as diagnostics of magnetosphere dynamics can often be restricted because of the uncertainties of earth induction effects. The vertical component of the magnetic field, in particular, has been restricted in its use because of its well known sensitivity to the earth's conductive structure. In this paper Parkinson's method and the transfer function method, together with a heuristic approach to induction phenomena, are used to analyze the effects of earth induction on ULF pulsations observed along a latitudinal network of stations near $L=4$ in the northern hemisphere and in their conjugate region at Siple, Antarctica. Results indicate that earth induction has little effect on the characteristics of pulsations in the Pc3, Pc4 and Pc5 frequency bands at these stations. Preliminary results establish the existence of important temporal variations of the in-phase induction vectors at Girardville and LacRebours and their correlation with external source-field mechanisms.
\end{abstract}

\section{Introduction}

This paper addresses the problem of ground induction effects on ULF magnetic pulsations observed at a latitudinal network of magnetometers near $L=4$ and in their conjugate region at Siple, Antarctica (cf. LANZERotri $e t a l$, 1972). Ground induction effects will affect ground based observations of changes in the geomagnetic field whether or not the earth in the vicinity of the observation site is homogeneous geoelectrically. Over a homogeneous finitelyconducting earth elementary considerations show that the induction mechanism tends to increase the magnitude of the horizontal fields and to decrease the magnitude of the vertical field. Hence, there is no significant effect on the polarization ellipse in the horizontal plane of a wave observed over a homogeneous earth. Wilson (1966), Annexstad and Wilson (1968), and Samson (1972) have pointed out however, that the polarization ellipse in the vertical planes may be appreciably distorted due to the induction-related decrease in amplitude of the 
vertical component. Phase changes between the vertical and horizontal components may also accompany the decreases in the vertical amplitude.

The data used in this paper were recorded at a latitudinal network of three magnetic stations located approximately on the $3.5^{\circ}$ geomagnetic meridian between $L \simeq 3.2$ and $L \simeq 4.4$ in the northern hemisphere. Local time at this longitude is five hours later than UT. Data from a fourth station (Siple, Antarctica)

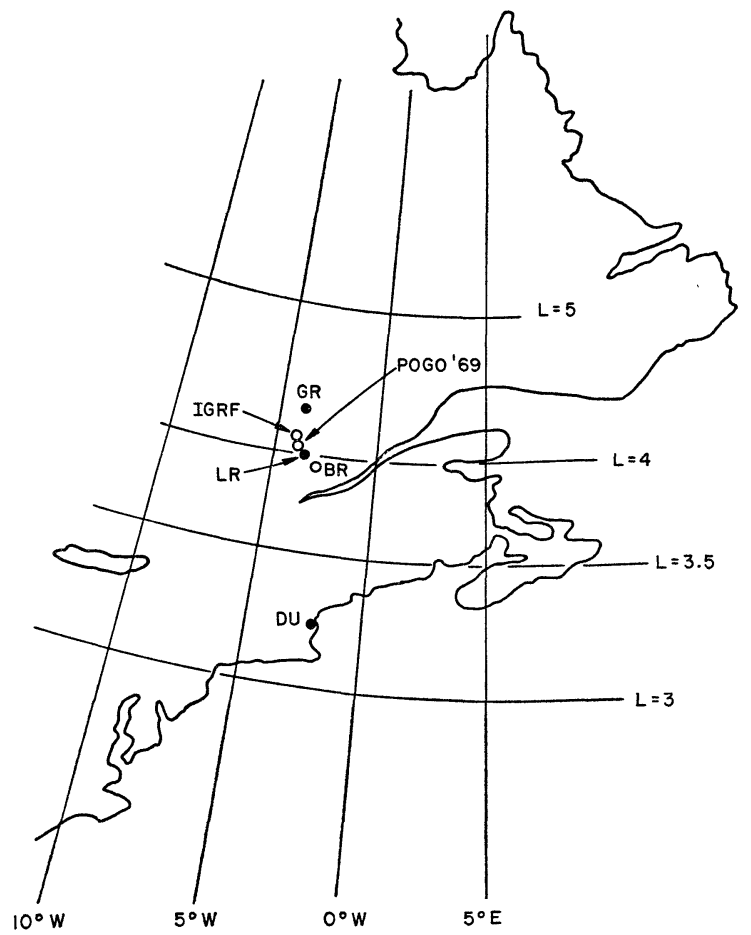

Fig. 1. Location of the three northern-hemisphere magnetometer stations in geomagnetic coordinates. The locations of the Siple, Antarctica, conjugate point (open circles) according to three field model calculations (from FUKUNISHI and LANZEROTті, 1974a).

Table 1. Location of magnetometer stations.

\begin{tabular}{lrrrrrr}
\hline \multirow{2}{*}{ Station } & \multicolumn{2}{c}{ Geographic } & & \multicolumn{2}{c}{ Geomagnetic } & \multirow{2}{*}{$L$ value } \\
\cline { 2 - 3 } & Latitude & Longitude & & Latitude & Longitude & \\
\hline Girardville & $49.00^{\circ} \mathrm{N}$ & $72.52^{\circ} \mathrm{W}$ & & $60.42^{\circ} \mathrm{N}$ & $3.68^{\circ} \mathrm{W}$ & 4.4 \\
LacRebours & $47.87^{\circ} \mathrm{N}$ & $72.45^{\circ} \mathrm{W}$ & & $59.29^{\circ} \mathrm{N}$ & $3.53^{\circ} \mathrm{W}$ & 4.0 \\
Durham & $43.10^{\circ} \mathrm{N}$ & $70.90^{\circ} \mathrm{W}$ & & $54.53^{\circ} \mathrm{N}$ & $1.43^{\circ} \mathrm{W}$ & 3.2 \\
Siple & $-76.00^{\circ} \mathrm{S}$ & $84.00^{\circ} \mathrm{W}$ & & $-64.76^{\circ} \mathrm{S}$ & $8.02^{\circ} \mathrm{W}$ & 4.0 \\
\hline
\end{tabular}


at $L \simeq 4.0$ was analyzed by the transfer function method, it being in the conjugate region of the other stations; cf. Fig. 1 ane Table 1. (More detailed information on these stations is found in Lanzerotri et al. (1972)). At each station a three component fluxgate magnetometer and associated data system samples the field at two second intervals with a resolution of $0.06 \gamma$ and dynamic range of $\pm 1000 \gamma$. All data was recorded digitally in a computer compatible format.

SAMSON (1972) has shown that induction over a homogeneous earth will be dominant at the earth's surface when

$$
\sigma f \lambda^{2}>5 \times 10^{6}
$$

where $\sigma$ is the earth conductivity in mks units, $f$ the frequency of the observed wave (or field variation), and $\lambda$ is the scale size of the pulsation phenomena. An upper bound estimate of ULF magnetic pulsation latitudinal scale size of $\sim 2 \times$ $10^{6}$ meters has been determined by the present author from observations made at the above latitudinal network of magnetometer stations near $L=4$. A reasonable lower bound for the continental conductivity would be $\sim 10^{-3} \mathrm{mhos} / \mathrm{m}$, thereby setting an upper frequency limit for nondominant induction effects at $\sim 1 \mathrm{mHz}\left(T=10^{3}\right)$. Pc 3-5 magnetic pulsations $(f \sim 2-30 \mathrm{mHz})$ observed over a homogeneous earth with conductivity greater than $10^{-3} \mathrm{mhos} / \mathrm{m}$ should therefore be affected by induction phenomena.

Although most changes in earth conductivity occur in the vertical direction, lateral variations in conductivity are probably of more importance to ULF pulsation studies because of their effect on horizontal polarization ellipses (RANKIN and RedDy, 1972; Wilson, 1966; SAMson, 1972). Such lateral variation in conductivity often take the form of two-dimensional conductive structures with a definite geographical orientation; well recognized examples are seacoasts and the vertical contacts between conducting sedimentary basins and resistive mountains.

Evidence for the location of the daytime plasma pause near $L=4$ as reported by FukUNishi and LANZERotTi $(1974 \mathrm{a}, \mathrm{b})$, is, in the main, based upon interpretations of ULF polarization characteristics in the horizontal plane and on systematic changes in spectral component peaks with latitude and local time. SAMSON (1972) has pointed out that normal induction over a homogeneous earth does not appreciably effect polarizations in the horizontal plane. However, induction due to two dimensional conductive structures may have an appreciable effect. It would, however, be difficult to explain the reported systematic polarization and amplitude variations with local time in terms of anomalous induction by two-dimensional conductive structures. The fact that Siple Station, Antarctica is situated on $\sim 6,500$ feet of ice (a good dielectric) should not have much effect on the observed ULF pulsations. (The ice depth at Siple has not 
been measured although this is the accepted value.) Girardville and LacRebours are inland and are situated on the highly resistive Canadian Shield some distance from both the St. Lawrence River and the boundary between the Canadian Shield and the Appalacian geologic provinces. Durham, due to its proximity to the Atlantic seacoast and other shallow saltwater bodies might experience the well known "coast effect" (PARkinson, 1959; SchmUCKer, 1970; HYNdman and Cochrane, 1971).

Evidence of induction effects on observed data usually appears with the alignment of the magnetic field components along a "preferred plane." PARKINsON (1959) used a graphical method based on simple differences of field component values to establish the "preferred plane" and defined an "arrow" which when aligned with the "preferred plane," pointed toward internal current concentrations. The more widely used transfer function method (cf. Cochrane and Hyndman, 1970; Schmucker, 1970; Banks, 1973), based on the relationship between the Fourier transforms of field components, defines an "induction vector." This vector, which lies in the "preferred plane," can by choice point either toward or away from internal current concentrations. Common usage, however, takes these arrows (or vectors) to point toward internal current concentrations.

This paper reports on the results of Parkinson's method applied to ULF magnetic pulsation data observed at the above Bell Laboratories Station near $L=4$. Parkinson's method, however, is limited to detecting only those two dimensional conductive structures that have redistributed the ULF fields such that the vertical and horizontal components covary roughly in-phase. This important consideration must be kept in mind when using this method.

Preliminary results are also presented on a preudo-vertical transfer function and induction vector analysis of the ULF magnetic pulsation field components observed on 22 December 1971 at all four of the above magnetometer stations. The results are presented on polar plots depicting the in-phase induction vectors as functions of time.

\section{Parkinson Plots}

Data for the Parkinson plot analysis were selected from a three-hour period for the day January 5, 1972. The hours selected included the intervals 1500 1600 UT, 1700-1800 UT and 2100-2200 UT for the three stations in the northern hemisphere and 1800-2100 UT for Siple Station. Data from January 5, were of particular interest because they contained considerable pulsation activity. This day has been analyzed in detail by Fukunishi and LANzerotti (1974a, b), and LANZEROTTI et al. (1974). 
The original magnetic variations of three components, in the form of time series length $T$, were low-pass filtered at two times the sampling interval $\Delta t$, to insure against aliasing. The net effect of selecting data of length $T$ and low-pass filtering is to band-pass the data with the frequency interval, $1 / T \leq f \leq 1 / 2 \Delta t$.

After applying the appropriate low-pass filter Parkinson plots were formed from the difference vectors computed at sampling intervals of $\Delta t=10,60$ and 120 seconds. The effect of low-pass filtering for $2 \Delta t=120$ seconds on the original magnetic variation $(H, D, Z)$ is observed by comparison of Figs. $2 \mathrm{a}$ and $2 \mathrm{~b}$.

OTNES and ENOCHSON (1972) have stated that the maximum resolvable frequency for a sampling interval $\Delta t$ is given by the relation:

$$
f_{\max }=2 / 5(\Delta t) \text {. }
$$
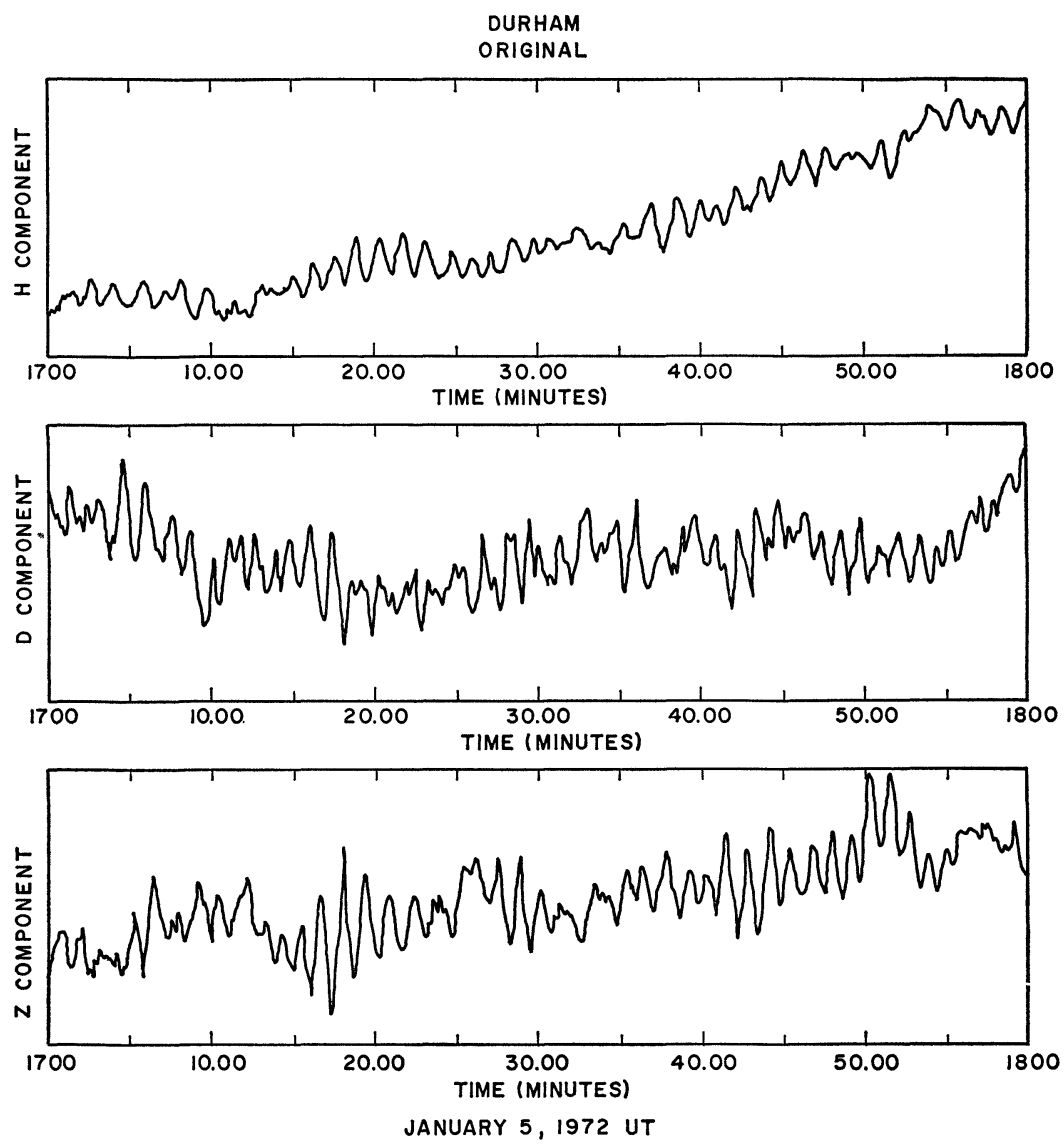

Fig. 2a. Observed $(H, D, Z)$ field components at Durham, in the interval 15001600 UT, January 5, 1972. 

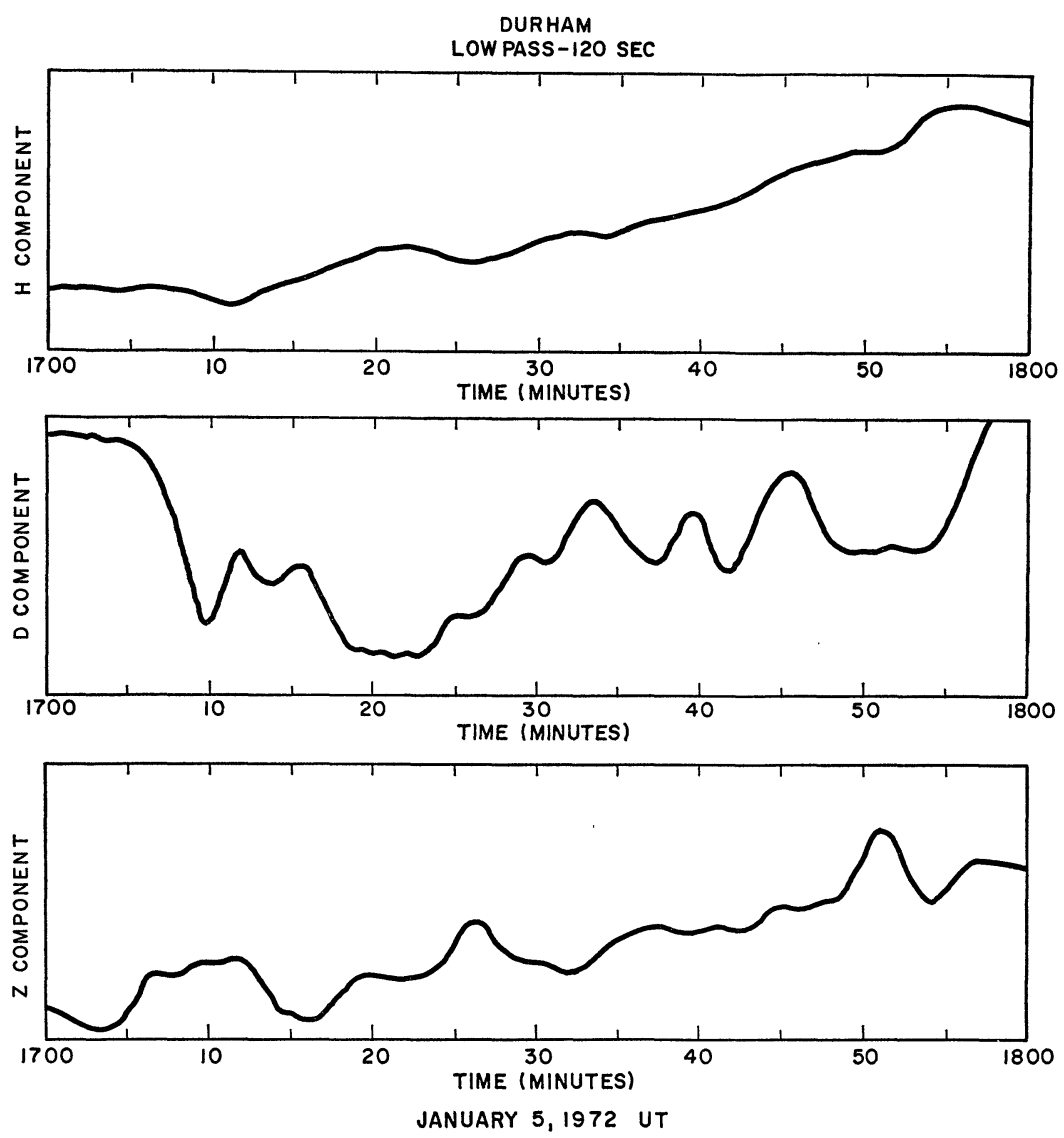

Fig. 2b. Low-pass filtered ( $2 \Delta t=120$ seconds) field components at Durham in the interval 1500-1600 UT, January 5, 1972.

Hence, for a data set of length $T=3$ hours on which a sampling interval of 60 seconds is taken the maximum resolvable frequency is $\sim 6.7 \mathrm{MHz}$. Parkinson plots formed at this sampling interval would give relevant information in the Pc5 frequency but would exclude the higher ULF pulsation frequencies. When the interval $\Delta t$ is set to 10 seconds the Parkinson plots would be applicable over the Pc3, Pc4 and Pc5 frequency bands. This gives some idea of the relevant frequency ranges represented by the Parkinson plots for a given sampling interval.

Parkinson plots for $\Delta t=60$ seconds are shown in Fig. 3 for each of the three northern stations. Similar plots for $\Delta t=120$ seconds are shown in Fig. 4.

The Parkinson plots at Girardville and LacRebours, Figs. 3 and 4 at $\Delta t=60$, 120 seconds show in general that there is little evidence of a preferred direction for the correlation between the vertical and horizontal ULF field components. 
Station 4 Day 4

Hour 15 Deltat 60SCS

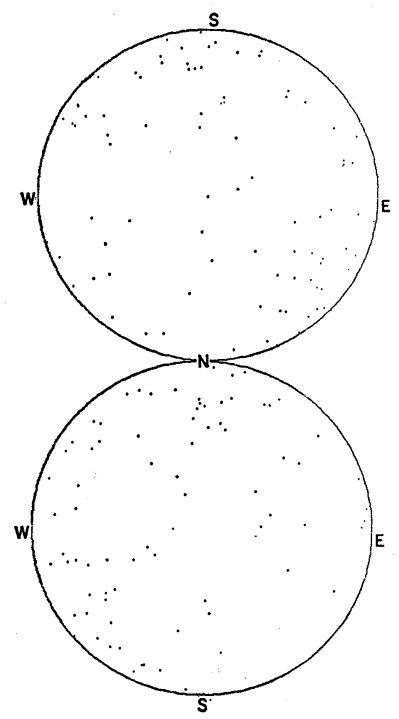

(a) Girardville
Station 2 Day 4

Hour 15 Deltat 60SCS

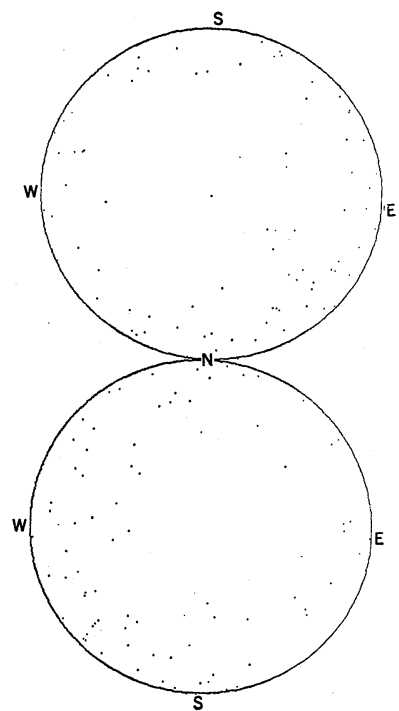

(b) LacRebours
Station 5 Day 4

Hour 15 Deltat 60SCS

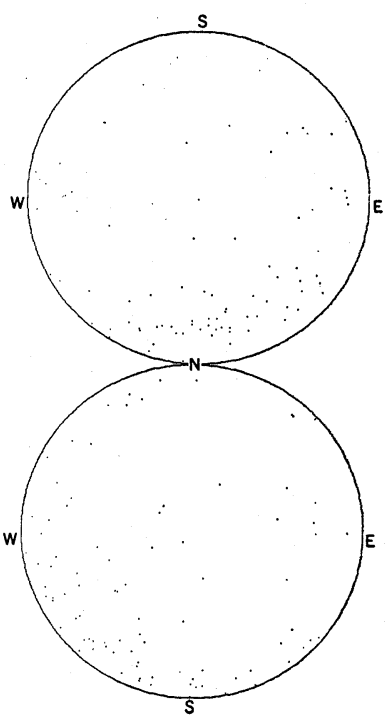

(c) Durham

Fig. 3. Parkinson plots January 5, 1972, $\Delta t=60$ seconds.

Station 4 Day 4

Hour 15 Deltat 120SCS

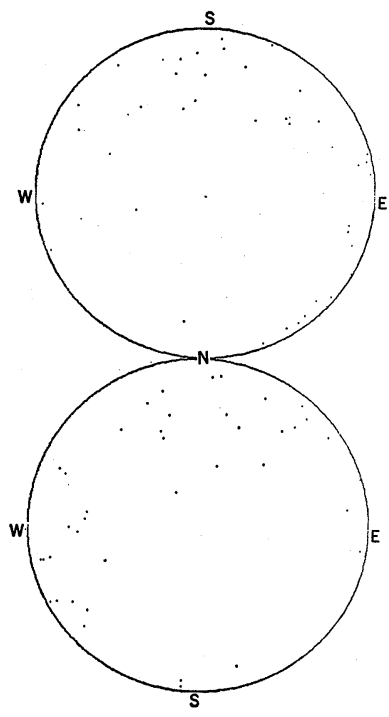

(a) Girardville
Station 2 Day 4

Hour 15 Deltat 120SCS

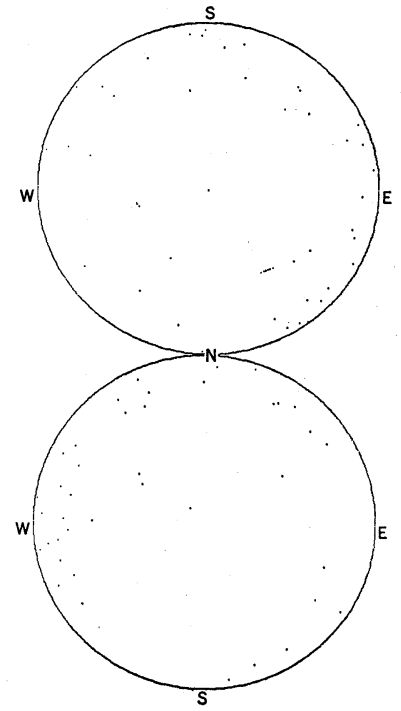

(b) LacRebours
Station 5 Day 4

Hour 15 Deltat 120SCS

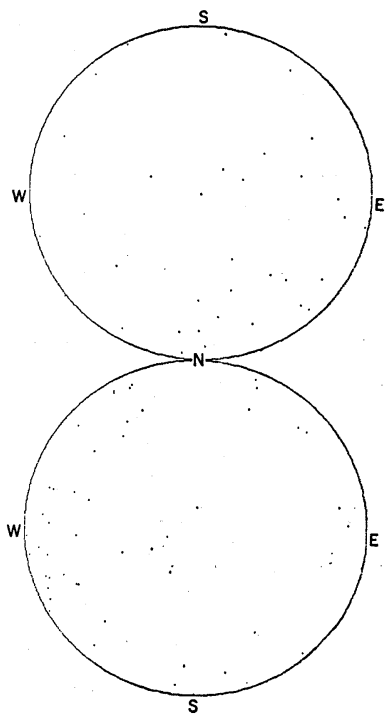

(c) Durham

Fig. 4. Parkinson plots January 5, 1972, $\Delta t=120$ seconds. 
At Durham, Figs. $3 \mathrm{c}$ and $4 \mathrm{c}$ for $\Delta t=60$ and 120 seconds, respectively, there is some evidence of a preferred plane tilting upward toward the northeast. It is not unlikely that this is associated with the conductivity boundary represented by the Atlantic coastline located some $25 \mathrm{~km}$ to the northeast Durham (see also below).

\section{Induction Vectors}

In an effort to substantiate the findings based on the Parkinson plot analysis and to obtain more information concerning the relationship between the ULF magnetic pulsation components, the complementary (BANKs, 1973) transfer function method of analysis was implemented, cf. SchmUCKer (1970).

Pseudo-vertical transfer functions similar to those employed by Cochrane and Hyndman (1970) using the observed horizontal components rather than 'normal' horizontal components were computed. From these vertical transfer functions, in-phase and quadrature-phase induction vectors were computed to assist in the interpretation of the transfer functions. The in-phase induction vectors are traditionally defined so as to point toward conductivity boundaries; i.e., internal current concentrations flowing along the boundary between high and low conductivity areas. It should be noted that in the event of external current concentrations in close proximity to the stations, e.g., the auroral electrojet, the so defined in-phase induction vector will point away from the current concentration. Possible evidence of such a source effect will be presented below.

\section{Transfer Function Computation}

Data from the same above four magnetometer stations was used in this analysis. The vertical transfer functions were computed from two-hour nonoverlapping power spectra for each of the three field components for the day 22 December 1971. This day immediately followed the magnetic storm period which began on 17 December 1971. The power spectra were derived from the FFT coefficients of each two-hour time series after application of a digital lowpass filter with a cut-off at $50 \mathrm{MHz}$ and a prolate spheroidal data window (THомSoN, 1971). Vertical transfer functions were computed for the 2-5 MHz, 10-15 $\mathrm{MHz}$ and 15-27 MHz frequency bands which correspond roughly to the Pc5, Pc4 and Pc3 ULF magnetic pulsation bands. In-phase and quadrature phase induction vectors were computed for the twelve two-hour intervals from 0000 2400 UT 22 December 1971 at each station for each of the three frequency bands. 
The results of the above vertical transfer function analysis for the Pc5 and Pc4 frequency bands are illustrated in Figs. 5 and 6. The in-phase induction vectors for each two-hour interval are plotted on a polar plot (cf. Figs. 5 and 6) where the radius represents the amplitude (or magnitude) of the vector and the

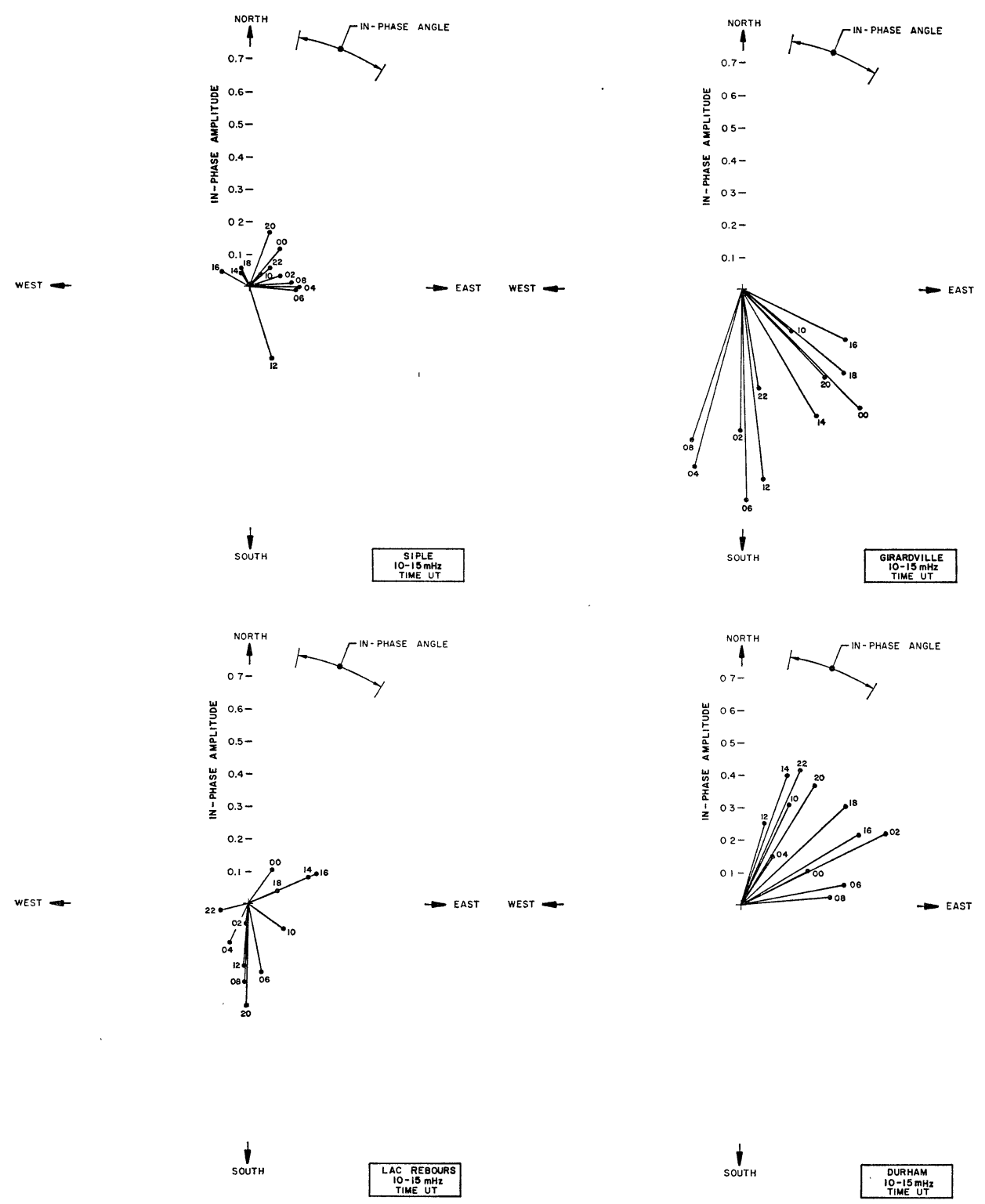

Fig. 5. Two-hour nonoverlapping in-phase induction vectors during December 22, 1971 for the Pc4 frequency band. 


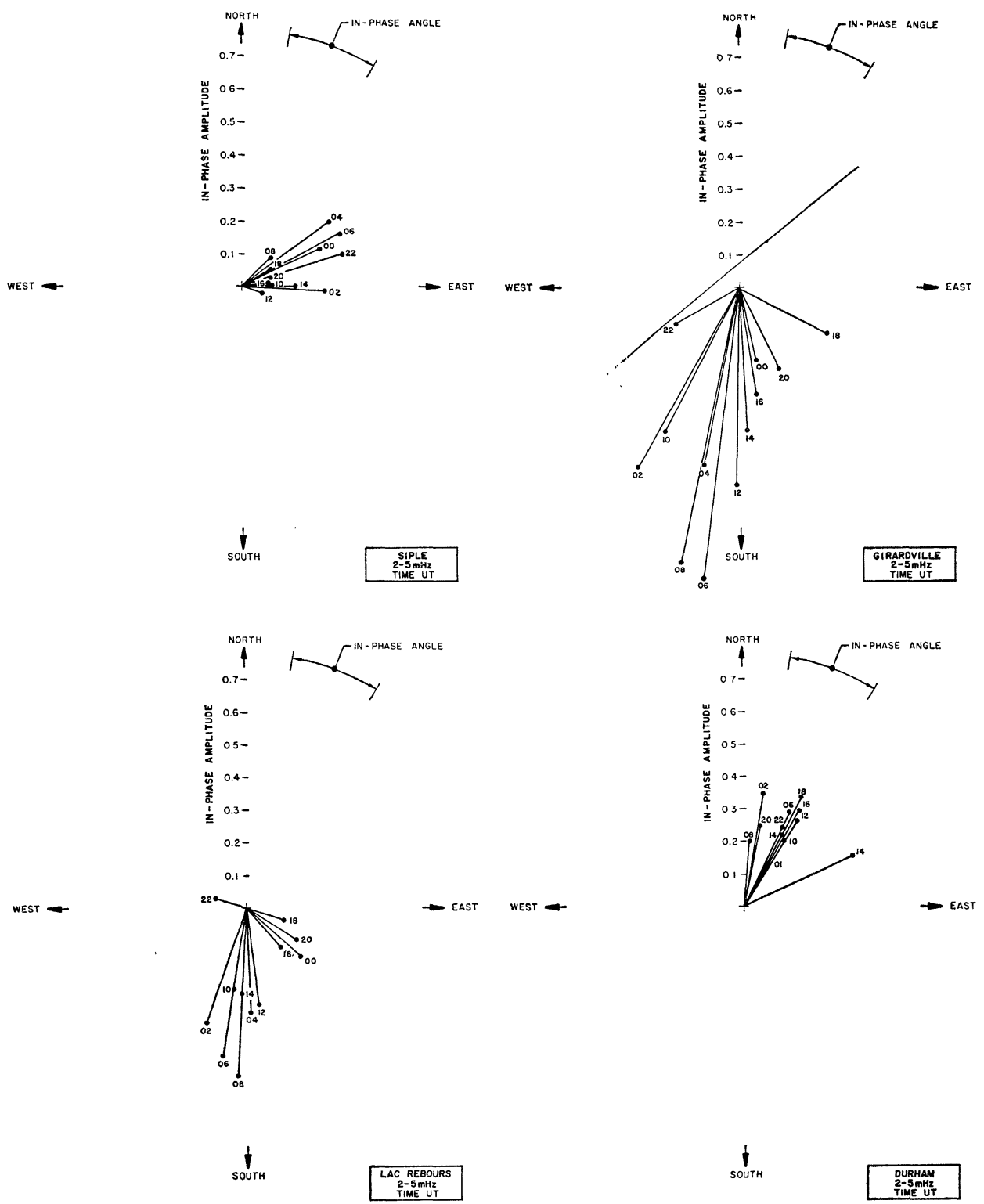

Fig. 6. Two-hour nonoverlapping in-phase induction vectors during December 22, 1971 for the Pc5 frequency band.

azimuthal angle represents its geographic direction with respect to magnetic north. The numbers at the tips of each vector represent the UT starting time of each two-hour interval. 
The outstanding features of the induction vector plots shown in Figs. 5 and 6 are:

1. Their relative size with respect to station location and

2. their somewhat orderly variation in azimuth with respect to local time. It should be noted that these features are different for the Pc4 and Pc5 frequency bands.

In the Pc5 band Siple and Durham have in general the smaller induction vectors which are confined to the northeast quadrant. Girardville and LacRebours have comparatively larger induction vectors which appear to vary widely in azimuth with local time. The largest vectors, however, are predominantly southward pointing.

In the Pc4 band Girardville and Durham have the largest induction vectors. The vectors for Durham are still confined to the northeast quadrant while those for Girardville vary over a wide angle in a predominantly southward direction. Both Siple and LacRebours have the smaller vectors which vary greatly in azimuth with local time. The possible correlation of the induction vectors to external and internal source currents are discussed below.

\section{Discussion}

The Parkinson plot and transfer function analyses both revealed evidence of preferred directions for the correlation of the vertical and horizontal ULF field components. It is well known that these techniques are capable of detecting the existence of either external or internal source currents, but they are not capable of discriminating between them. A plausible technique to resolve this ambiguity can be based on the argument that external currents vary spatially with time due to their association with magnetospheric processes while internal source currents, particularly those associated with two-dimensional conductive structures, are in the main stationary with respect to time.

The induction vector polar plots, Figs. 5 and 6 suggest that the azimuthal variation of the vectors at several of the stations can be correlated temporally with the spatial movement of the observed external localized source currents.

To aid in determining the location of the localized ULF pulsation source (i.e., the external source currents), with respect to latitude and local time (cf. Fununishi and Lanzerotti, 1974a, b), contour plots of the $H$ and $D$ component magnetic power in the Pc5 and Pc4 bands are presented in Fig. 7, after LANZEROTTI et al. (1976). These plots were obtained by normalizing the spectral power in each band to the station with a maximum intensity for each of the twohour intervals. Linear interpolation was used to produce contours between stations. The contour plots indicate that the source location for Pc5 frequency 


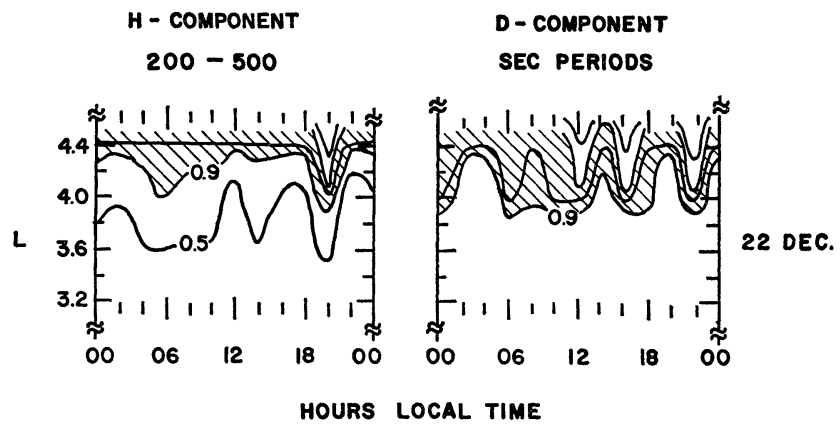

(a)

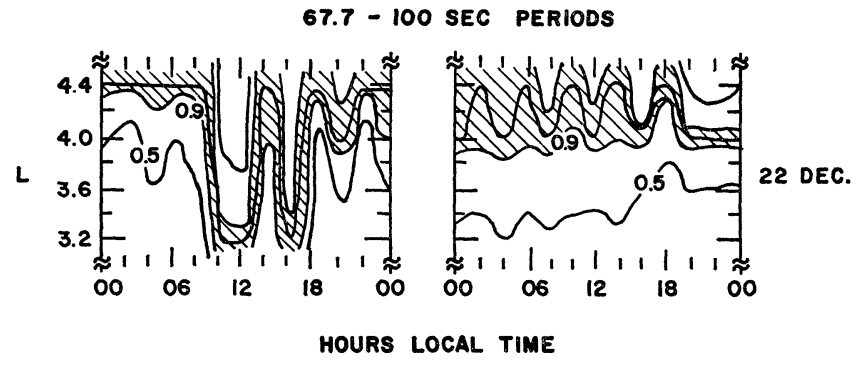

(b)

Fig. 7. Contour plots of ULF power in the Pc4 and Pc5 frequency bands near $L=4$ during 22 December 1971 (after LANzerotTi et al., 1975).

variations was always north of the northern most station $(L \sim 4.4)$, as expected (SAmson, 1972). The source location for Pc4 as implied from maximums in the $H$ component contours and other indicators (FUKUNISHI and LANZEROTTI, 1974b) are seen to move in latitude with local time. The southern most progression of the Pc4 source as shown in Fig. 7a, tends to occur around 1200 LT.

The spatial and temporal characteristics of the induction vectors and their possible association with either internal or external source currents are now discussed for each station individually. Also, where appropriate, comparisons will be made to the Parkinson plots.

\subsection{Girardville}

The most obvious feature of Fig. 6 is the large magnitude of the in-phase vectors produced in the postmidnight LT sector. This feature would coincide with the intensification and/or southward movement of the Pc5 source as reported by SAMSON (1972). The azimuthal direction of these vectors is definitely south, which is consistent with the interpretation that in-phase induction vectors point away from external source currents. Figure $7 \mathrm{~b}$ shows that the maximum $H$ component contour occurs no further south than $L \sim 4.4$. 
Figure 5 shows that at Pc4 frequencies the in-phase vectors point predominantly south even though there appears to be some northward swing to the in-phase vectors around local noon. $H$ component contours in Fig. 7a show a distinct southward and northward movement of the source between 0900 LT and $1800 \mathrm{LT}$. A precise correlation of the localized source to the in-phase vector direction is not conclusive; this may be attributed to the degree of source localization as well as the inherent smoothing effect of two-hour nonoverlapping power spectral estimates.

The Parkinson plots, Figs. 3a and 4a, show no evidence of a preferred plane.

\subsection{LacRebours}

Figure 6 for the LacRebours results shows that the Pc5 band in-phase vectors south throughout the day and the magnitudes are not nearly as large as those at Girardville. This may be a consequence of the increased distance of this station from the Pc5 source location. In the Pc4 band Fig. 5 shows that the in-phase vectors change their direction and magnitude significantly throughout the day. This appears to be consistent with the evidence given by Fig. 7a revealing that the Pc4 source location has moved southward past $L \sim 4$ (LacRebours) and back northward between the hours 0900 LT and 1800 LT. Again the Parkinson plots, Figs. $3 \mathrm{~b}$ and $4 \mathrm{~b}$ show no real preferred plane.

\subsection{Durham}

Figures 5 and 6 show that the in-phase vectors at Durham consistently point in a northeasterly direction throughout the day. The magnitudes of the vectors in the Pc5 band are smaller than those at either Girardville and LacRebours. It is felt that these vectors are a manifestation of internal current concentrations associated with the redistribution of the external horizontal magnetic components by a lateral conductivity inhomogeneity. It is likely that this inhomogeneity is associated with the Atlantic Ocean coastline located some $25 \mathrm{~km}$ to the northeast of Durham. The accompanying quadrature phase induction vectors (not shown) of comparable magnitude are consistent with induction effects resulting from a shallow penetration of the external field into the continent and ocean (Hyndman and Cochrane, 1971). This effect is not unexpected in the Pc4 and Pc5 frequency bands. In this instance the Parkinson plots, Figs. $3 \mathrm{c}$ and $4 \mathrm{c}$ both show a weak tendency for a preferred plane to tilt upward toward the northeast corroborating the induction vector results. The weakness of the correlation may be ascribed to that fact that the $D$-component does not have much power as well as to the fact that there is a considerable quadrature component associated with the induction vectors.

Durham is the only station at which the preferred direction of correlation 
SIPLE $(L=4.0)$
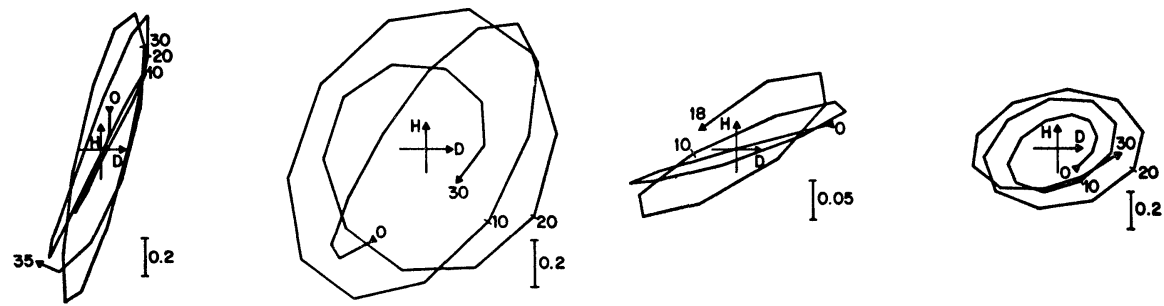

GIRARDVILLE ( $L=4.4$ )
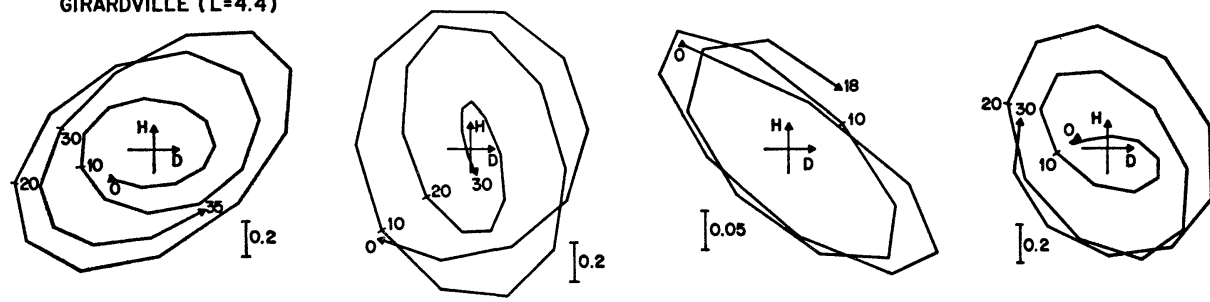

LAC REBOURS $(L=4.0)$
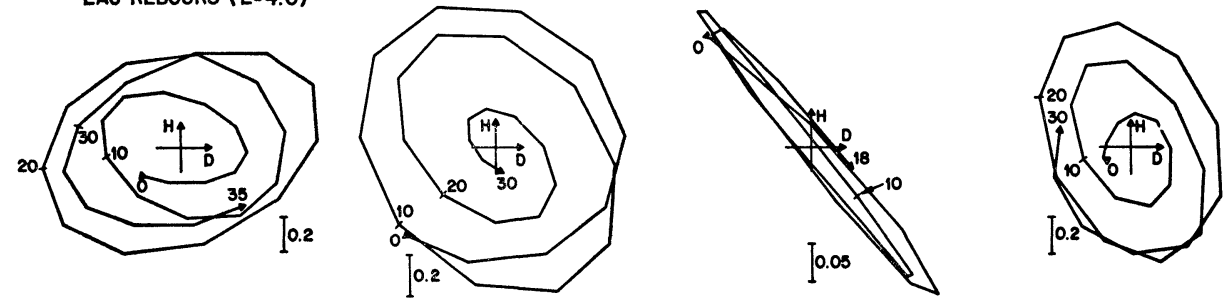

DURHAM $(L=3.2)$

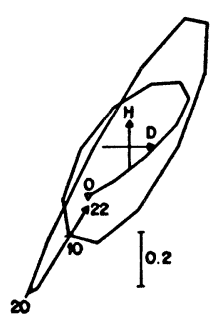

$07 \mathrm{~h} 40 \mathrm{~m} 52 \mathrm{~s}-46 \mathrm{~m} 36 \mathrm{~s}$ FILTER: $60-120 \mathrm{sec}$

(a)

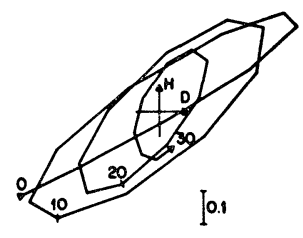

IIh 05m 40s-09m 40s FILTER : $60-100 \mathrm{sec}$

(b)

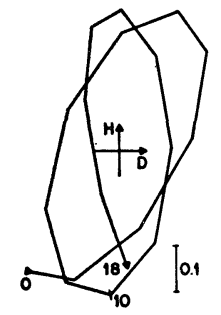

$15 \mathrm{~h} 54 \mathrm{~m} 36 \mathrm{~s}-57 \mathrm{~m}$ 00s FILTER : $55-90 \mathrm{sec}$

(c)

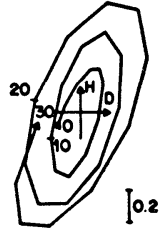

21 h $18 \mathrm{~m} 36 \mathrm{~m}-22 \mathrm{~m} 36 \mathrm{~s}$ FILTER : $60-110 \mathrm{sec}$ (d)

Fig. 8. Wave hodograms for four events in the Pc4 frequency band (After FuKUNISHI and LANZEROTTI, 1974). 
between the vertical and horizontal field components remained fairly stationary with local time. The possibility exists that the disturbing lateral conductivity inhomogeneity may also appreciably affect the field components in the horizontal plane in a way similar to that reported by SAMson (1972).

Direct evidence that this is not the case is presented in Fig. 8. In this figure are shown wave hodograms in the horizontal plane for four events in the Pc4 frequency bands during January 5, 1972 at each of the Bell Laboratory magnetometer stations. The important angles of polarization at each station are seen to vary with time in a systematic way, which is consistent with their being associated with external source currents. This supports the interpretation that the anomalous fields associated with the "coast effect" at Durham do not dominate the 'normal' fields in the horizontal plane. Hence, the nonuniformities observed in the horizontal fields at Durham are due in the main to external source current effects. It would though be interesting to analyze the degree of polarization in the horizontal plane as a function of local time.

\subsection{Siple}

The in-phase vectors in Figs. 5 and 6 are very small and do not appear to significantly change direction throughout the day. It is difficult from Figs. 5a and $6 \mathrm{a}$ to determine if the induction vectors are influenced primarily by external or internal current concentrations. Any further interpretations of the induction vectors at Siple would require extensive analysis of both the in-phase and quadrature phase induction vector variations with local time as well as comprehensive comparisons with its conjugate station in the northern hemisphere.

\section{Conclusion}

The systematic application of a combination of techniques to analyze the temporal and spatial variations of ULF field components has shown that earth induction has little or no effect on their horizontal polarization characteristics. Evidence of a weak "coast effect" was found at Durham in the Pc4 and Pc5 frequency bands. The induction vector plots proved particularly helpful in determining whether the observed field nonuniformities were mainly of an external or an internal origin. The observed systematic changes of the induction vectors at Girardville and LacRebours in the Pc4 and Pc5 frequency bands calls into serious question the common practice in ground induction studies of averaging these vectors over many time intervals in an effort to nullify the source effect.

The author thanks C.G. Maclennan, Bell Telephone Laboratories for her assistance with data preparation and handling. Also thanks go to Dr. L.J. Lanzerotti, Bell Telephone Labo- 
ratories, for use of his ULF magnetic pulsation data, his in-depth queries, and profitable discussions.

\section{REFERENCES}

Annexstad, J.O. and C.R. Wilson, Characteristics of Pc micropulsations at conjugate points, J. Geophys. Res., 73, 1805-1818, 1968.

BANKs, R.J., Data processing and interpretation in geomagnetic deep sounding, Phys. Earth Planet. Inter., 7, 339-348, 1973.

Cochrane, N.A. and R.D. Hyndman, 1970, A new analysis of geomagnetic depth-sounding data from western Canada, Can. J. Earth Sci., 7, 1208-1218, 1970.

FunUnishi, H. and L.J. LANZerotTi, ULF pulsation evidence of the plasmapause, I. Spectral studies of Pc3 and Pc4 pulsations near L=4, J. Geophys. Res., 79, 142-158, 1974a.

FukUnishi, H. and L.J. LANZerotti, ULF pulsation evidence of the plasmapause, II. Polarization studies of Pc3 and Pc4 pulsations near $L=4$ and at a latitude network in the conjugate region, J. Geophys. Res., 79, 4632-4647, 1974b.

Hyndman, R.D. and N.A. Cochrane, Electrical conductivity structure by geomagnetic induction at the continental margin of Atlantic Canada, Geophys. J.R. astr. Soc., 25, 425-446, 1971.

LANZerotti, L.J., H. FukUnishi, and L. Chen, ULF pulsation evidence of the plasmapause, III. Interpretation of polarization and spectral amplitude studies of Pc3 and Pc4 pulsation near $L=4, J$. Geophys. Res., 79, 4648-4653, 1974.

Lanzerotti, L.J., A. Hasegawa, and N.A. Tartaglia, Morphology and interpretation of Magnetospheric plasma waves as conjugate points during December solstice, J. Geophys. Res., 77, 6731-6745, 1972.

Lanzerotti, L.J., C.G. Maclennan, and H. Fukunishi, ULF Geomagnetic power near $L=$ 4, 5. Cross-power spectral studies of geomagnetic variations $2-27 \mathrm{MHz}$ in conjugate areas, J. Geophys. Res., 1976 (to be published).

Otnes, R.K. and L. Enochson, Digital Time Series Analysis, p. 33, John Wiley and Sons, New York, 1972.

Parkinson, W.D., Directions of rapid geomagnetic fluctuations, Geophys. J.R. astr. Soc., 2, 1$13,1959$.

RANKIN, D. and I.K. REDDY, Effect of geoelectric structure on the polarization characteristics of the geomagnetic micropulsations, J. Geophys. Res., 77, 1286-1291, 1972.

Samson, J.C., Three-dimensional polarization characteristics of high-latitude Pc5 geomagnetic micropulsations, J. Geophys. Res., 77, 6145-6160, 1972.

SchmUCKer, U., Anamalies of geomagnetic variations in the southwestern United States, Bull. Scripps Inst. Oceanography, 13, 1970.

SchmUCKer, U., Interpretation of induction anomalies above nonuniform surface layers, Geophysics, 36, 156-165, 1971.

Thomson, D.J., Ph.D. Dissertation, Polytechnic Institute of Brooklyn, New York, 1971.

WILson, C.R., Conjugate three-dimensional polarization of high-latitude micropulsations from a hydromagnetic wave-ionospheric current model, J. Geophys. Res., 71, 3233-3249, 1966. 